Work on plant protection was confined chiefly to entomological investigations, the most serious threat to groundnut production coming from the presence of Hilda patruelis. It is expected that the virus causing rosette will cause trouble in the near future ; but in the 1948 season diseases do not seem to have been serious.

Investigations on the quality of the groundnut oils produced at Kongwa by Prof. T. P. Hilditch, of the University of Liverpool, showed that they were of very high quality, and in colour and free acidity they "far surpass any raw groundnut oil which has hitherto been on the English market". The oils had an excep. tionally high iodine value, but were liable to deteriorate in presence of moisture.

An Operational Research Unit was established in 1949 to carry out research on land-clearing, agricultural, civil-engineering and transport problems, as it had been found that tests made in England on plant and equipment had little value for East African conditions. The Unit has had considerable success in developing a chain-cable clearing of bush. A heavy. 3 -inch chain cable is attached to two heavy tractors which move through the bush 20-30 ft. apart, and a third tractor follows to deal with particularly stout trees which the chain cable cannot pull out of the ground. The successful application of this method of flattening is cited as the outstanding achievement of the year, and promises to effect great economies in the cost of clearing, although at Kongwa it has considerably increased the wastage of tractors.

\section{G. V. JACKS}

\section{INFLUENCE OF ORGANIC NITROGEN COMPOUNDS ON NITRIFICATIONS IN SOIL}

\author{
By Prof. J. H. QUASTEL, F.R.S. \\ AND \\ DR. P. G. SCHOLEFIELD
}

\section{Montreal General Hospital Research Institute, Montreal}

$\mathrm{T}$ HE following report is intended to summarize briefly some of the main findings discovered in an investigation of the metabolism of organic nitrogen compounds in soil, with particular reference to the breakdown of amino-acids and certain allied substances. They throw light on the problem of the interference of organic matter with soil nitrification and on the chemical nature of a number of molecules that appear specifically to affect ammonia metabolism. They also point to the presence in soil of a class of organisms that can convert certain organic nitrogen compounds directly into nitrites. This report must be regarded as a preliminary statement ; full details of the experimental techniques and results (together with many that cannot adequately be mentioned here) will be given in later publications.

The method of investigation is that of continuous perfusion of a solution of the substance under investigation through a column of $30 \mathrm{gm}$. air-dried crumbed soil, under conditions where optimal aeration together ith water saturation, but no waterlogging, occurs. method of soil perfusion has already been acribed by Lees and Quastel ${ }^{1}$ in their studies ion in soil; but the apparatus now used is Audus's modification ${ }^{2}$ of the original one used by the above workers. Among the various conclusions reached by Lees and Quastel the following bear upon the subject of the present inquiry.

(1) When nitrification takes place in a soil, the nitrifying organisms develop largely on the surfaces of the soil crumbs. During the initial perfusion of an air-dried soil this process may be of long duration, since the logarithmic growth phase is involved; but eventually a condition arises when the sites of proliferation on the soil are saturated with the nitrifying organisms. The soil is then termed a saturated or enriched soil. Such a soil brings about a relatively rapid rate of nitrification, and this rate remains constant during subsequent perfusion of the soil with ammonium chloride. The soil, in fact, behaves like an enzyme system, no proliferation of the relevant organisms taking place except presumably to replace the dead cells.

(2) A saturated soil that nitrifies an ammonium salt at a constant rate and shows no initial lag period will not nitrify organic nitrogen compounds such as methylamine, trimethylamine and glycine at constant rates. A lag period occurs, showing that organisms must first develop that can convert these compounds into free ammonia which is afterwards nitrified. On the other hand, it was found that nitrification of pyruvic oxime shows little or no lag, and it seemed possible that this molecule may play a significant part in the process of nitrification.

\section{Nitrification of Ammonium Chloride and Glycine}

If the conversion of glycine into nitrate by soil bacteria always requires the intermediate production of the ammonium ion, it follows that the rate of nitrification of glycine should never exceed that of ammonium chloride, under identical experimental conditions and for equal quantities of nitrogen. Experiment, however, shows that this is not always the case. A few typical results are shown in Table 1.

Table 1

\begin{tabular}{|c|c|c|c|c|c|}
\hline \multirow{3}{*}{$\begin{array}{l}\text { Garden } \\
\text { soils }\end{array}$} & \multirow{3}{*}{$p \mathrm{H}$} & \multicolumn{4}{|c|}{$\begin{array}{l}\mu \mathrm{gm} \text {. } \mathrm{NO}^{\prime}-\mathrm{Nitrogen} / \mathrm{ml} \text {. formed on con- } \\
\text { tinuous perfusion at } 70^{\circ} \mathrm{F} \text {. Maximum } \\
\text { possible }=140 \mu \mathrm{gm} . / \mathrm{ml} \text {. }\end{array}$} \\
\hline & & \multicolumn{2}{|c|}{$\begin{array}{c}\text { Ammonium chloride } \\
(0.01 M)\end{array}$} & \multicolumn{2}{|c|}{$\begin{array}{r}\text { Glycine } \\
(0.01 M)\end{array}$} \\
\hline & & $\begin{array}{c}\text { First } \\
\text { perfusion } \\
\text { (15 days) }\end{array}$ & $\begin{array}{l}\text { Second } \\
\text { perfusion } \\
\text { (13 days) }\end{array}$ & $\begin{array}{l}\text { First } \\
\text { perfusion } \\
\text { (15 days) }\end{array}$ & $\begin{array}{l}\text { Second } \\
\text { perfusion } \\
\text { (13 days) }\end{array}$ \\
\hline II & $\begin{array}{l}4 \cdot 5 \\
6 \cdot 5 \\
7 \cdot 6\end{array}$ & $\begin{array}{r}10 \\
82 \\
113\end{array}$ & $\begin{array}{r}\overline{18} \\
104\end{array}$ & $\begin{array}{r}10 \\
134 \\
140\end{array}$ & $\overrightarrow{98}$ \\
\hline
\end{tabular}

Here it will be seen that with a soil of $p H 6.5$ the rate of nitrification of glycine exceeds that of ammonium chloride and that such a soil on perfusion with glycine may become enriched with nitrifying organisms while the same soil perfused with an equimolar solution of ammonium chloride fails to show such an enrichment. A neutral or slightly alkaline soil, on the other hand, favours the nitrification of ammonium chloride rather than that of glycine, while a distinctly acid soil $(p H \mathbf{H} \cdot 5)$ fails to nitrify either molecule satisfactorily. The phenomenon whereby a slightly acid soil (and many agricultural soils are of this nature) brings about a preferential nitrification of an organic nitrogen compound such as glycine must, of course, be of 




Fig. 1. Kinetics of nitrate formation during soil perfusion of ammonium chloride and amino-acids

$A, 0.01 M$ ammonium chloride; $B, 0.01 M$ glycine; $C, 0.01 M$ alanine; $D, 0.01 M$ glutamate; $E, 0.01 M$ methionine

importance in agricultural practice and should be considered in connexion with fertilizer problems. The reason for this preferential nitrification of glycine rather than of ammonium chloride is not difficult to discover.

When nitrification of one ammonium ion takes place, two hydrogen ions are liberated, thus :

$$
\mathrm{NH}_{4}^{+}+2 \mathrm{O}_{2} \rightarrow 2 \mathrm{H}^{+}+\mathrm{NO}_{3}^{-}+\mathrm{H}_{2} \mathrm{O} \text {. }
$$

Unless, therefore, the medium in which nitrification takes place is well buffered, the process must eventually cease on account of the decreased $p \mathrm{H}$. The optimal $p \mathrm{H}$ for nitrification (in pure culture), as Meyerhof ${ }^{3}$ has shown, is $p H$. When glycine is nitrified the following is the end result:

${ }^{+} \mathrm{NH}_{3} \cdot \mathrm{CH}_{2} \cdot \mathrm{COO}^{-}+7(\mathrm{O}) \rightarrow 2 \mathrm{CO}_{2}+2 \mathrm{H}_{2} \mathrm{O}+\mathrm{H}^{+}+\mathrm{NO}_{3}{ }^{-}$. In this case, only one hydrogen ion is liberated per molecule of glycine apart from the production of carbon dioxide, and hence the production of acidity will not be as great as in the nitrification of an ammonium salt of a mineral acid.

It follows, if this reasoning is correct, that the administration of sodium bicarbonate or calcium carbonate with ammonium chloride should serve to neutralize the acids formed during nitrification and prevent any decrease in the rate of this process. Results given in Table 2 show the truth of this con. clusion, which is, of course, already well known in agricultural practice. Simple admixture of the soil with calcium carbonate will convert a soil that poorly nitrifies ammonium chloride into a rapidly nitrifying soil which easily becomes saturated. Further experiment shows that admixture of the substrate with the sodium salts of organic acids such as acetic, pyruvic

\section{Table 2}

$\mu \mathrm{gm}$. Nitrate nitrogen $/ \mathrm{ml}$. formed on continuous perfusion at $70^{\circ} \mathrm{F}$, Local garden soil. Maximum $=140 \mu \mathrm{gm} . / \mathrm{ml}$.

Perfusate

Ammonium chloride $(0.01 \mathrm{M})$

Ammonium chloride $(0.01 M)$ and

sodium bicarbonate $(0.01 M)$

Ammonium chloride $(0 \cdot 01 M)$ and $1 \mathrm{gm}$. calcium carbonate added to
soil

$\begin{array}{ccc}\begin{array}{c}\text { First } \\ \text { perfusion } \\ \text { (7 days) } \\ 67\end{array} & \begin{array}{c}\text { Second } \\ \text { perfusion } \\ (3 \text { days }) \\ \mathbf{1 5}\end{array} & \begin{array}{c}\text { Third } \\ \text { perfusion } \\ \text { (3 days) }\end{array} \\ \mathbf{9 3} & 30 & - \\ 125 & 99 & 98\end{array}$

and succinic, has the same effect as admixture with sodium bicarbonate; that is, that of preventing too great an increase of acidity during nitrification. due to the formation of sodium bicarbonate, and therefore of apparently stimulating nitrification of ammonium salts of mineral acids. It is evident that on slightly acid soils the salts of organic acids do not necessarily depress the rate of nitrification; on the contrary, they may favour it.

\section{Recovery of Organic Nitrogen as Nitrate during Soil Nitrification}

While the recovery of the nitrogen of the ammonium salt of a mineral acid as nitrate during the continuous perfusion through soil is very nearly 100 per cent, this is not the case with the nitrogen of $\alpha$-aminoacids. Typical results shown in Table 3 indicate that the recovery decreases with increase in the $\mathrm{C} / \mathrm{N}$ ratio of the amino-acid. This conclusion is to be expected as the heterotrophic organisms proliferating at the expense of the amino-acid must use part of the nitrogen for their development. The greater the quantity of carbon available for proliferation purposes, the greater will be the quantity of nitrogen which will be used to support this proliferation. Hence the smaller will be the quantity of nitrogen which will be available as ammonia for the disposal of the nitrifying organisms. This is an illustration of the well-known fact that the presence of assimilable carbon in the soil diminishes the availability of ammonia or nitrate nitrogen to the plant.

\section{Table 3}

Percentage recovery of perfused organic nitrogen as nitrate nitrogen on continuous perfusion through soil at $70^{\circ} \mathrm{F}$. for 15 days Maximum absolute recovery possible $=140 \mu \mathrm{gm} . / \mathrm{ml}$. Source of nitrogen

$\begin{array}{cc}\begin{array}{c}\text { Recovered as } \\ \text { nitrate nitrogen } \\ (\mu \mathrm{gm} . / \mathrm{ml} .)\end{array} & \begin{array}{c}\text { Percentage } \\ \text { recovery }\end{array} \\ 138 & 98 \cdot 5 \\ 135 & 96 \cdot 5 \\ 118 & 84 \cdot 0 \\ 95 & 68 \cdot 0\end{array}$

Ammonium chloride Glycine $d l$-Alanine
$d l$-Sodium glutamate $84 \cdot 0$
$68 \cdot 0$

\section{Rates of Nitrification of Amino-Acids in Soil}

The rates of nitrate formation from such aminoacids as glycine, alanine and glutamic acid on continuous perfusion through a well-buffered garden soil $(p H \quad 7 \cdot 2)$ do not differ markedly from that from ammonium chloride when used at equivalent concentrations. Some results are shown in Fig. 1. This would indicate that in spite of the development of heterotrophic organisms which capture part of the available nitrogen, sufficient ammonia is produced to encourage the proliferation of nitrifying organisms at nearly optimal rates. Such a result proves that, under soil conditions, the presence of organic matter, in the form of the simple amino-acids quoted, is no hindrance to the process of nitrification. The initial lag periods in the course of nitrification of the three amino-acids are of the same order as that of ammonia itself.

An entirely different picture presents itself when $d l$-methionine is studied. It suffers no nitrification even after fourteen days continuous perfusion (see Fig. I).

\section{Selective Inhibitory Action of d/-Methionine on Nitrification}

$D l$-methionine has a highly inhibitory effect on the nitrification of ammonium ions in soil. In an experiment in which the rate of ammonium ion conversion into nitrite, during soil perfusion, was investigated by means of the addition of $0.001 M$ 


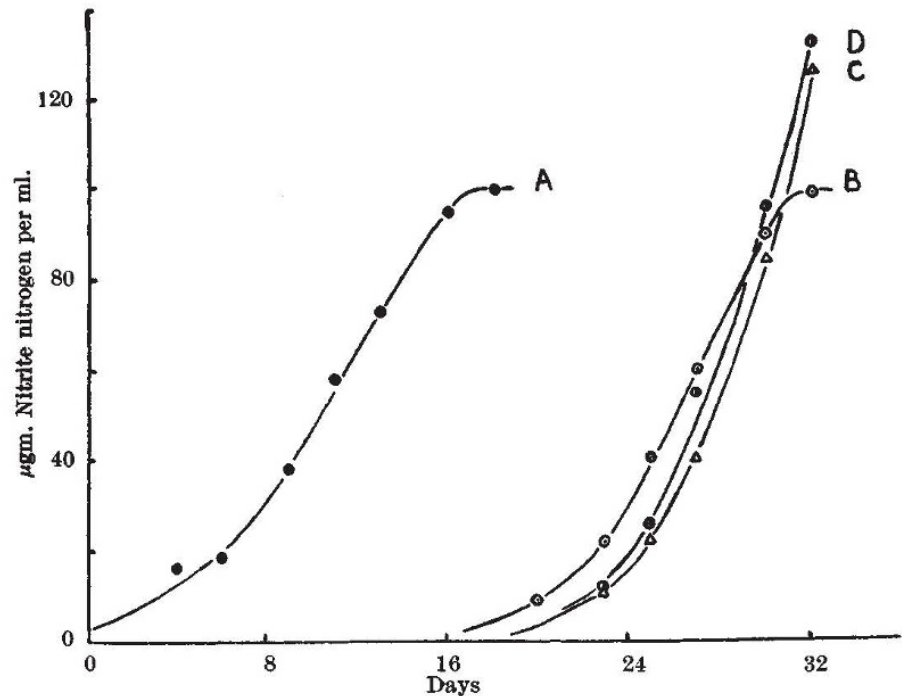

Fig. 2. Fffects of $d l$-methionine on the kinetics of nitrite formation during soll perfusion $A,(0.01 M)$ ammonium chloride; $B,(0 \cdot 01 M)$ methionine; $C,(0.01 M)$ methionin $+(0.01 M)$ ammonium chloride; $D,(0.01 M)$ methionine $+(001 M)$ glycine

nitrification. Eventually, after about ten days, nitrite metabolism takes place even in the presence of $d l$-methionine which, itself, has not yet suffered decomposition. It would follow that the nitrite-oxidizing organisms may adapt themselves to the inhibitory action of the methionine. This phenomenon of the adaptation of nitrite. oxidizing organisms to a variety of toxic substances will be the subject of another communication.

\section{Inhibitory Effects of Ethyl Urethane}

As shown by Meyerhof ${ }^{3}$ working with pure cultures of nitrifying organisms, and by Lees and Quastel ${ }^{1}$ in investigating the process of nitrification in soil, ethyl ure. thane inhibits the conversion of ammonium ions into nitrate. This phenomenon takes place with an enriched soil; so it would appear that urethane is acting as a poison to ammonia metabolism. Typical results showing the effect of ethyl urethane on the nitrification of ammonium chloride in a fresh garden soil are shown in Fig. 5, where

potassium chlorate, which prevents the development of Nitrobacters, it was found that $d l$-methionine $(0.005 M)$ greatly retards the rate of nitrite formation from ammonia or glycine. Only when, eventually, methionine itself is broken down, does nitrite appear from the ammonium ions or from glycine. These results are illustrated in Fig. 2. It is evident from this result that $d l$-methionine represents an organic molecule having a highly inhibitory effect on the ammonia metabolism of Nitrosomonas. The mechanism of this inhibition awaits further investigation.

\section{Inhibitory Action of Thiourea on Nitrification}

Further work has shown that thiourea exerts an even more profound inhibitory effect than $d l$-methionine on the nitrification of ammonia in soil. Results given in Fig. 3 show that thiourea at a concentration of $0.00033 M$ will entirely prevent the nitrification of ammonium chloride even after a lapse of sixteen days. No indications have been obtained as yet that thiourea itself will undergo nitrification or will permit this process to take place in its presence.

\section{Amino-Acids and Nitrite Oxidation in the Soil}

The presence of $\alpha$-amino-acids tends to retard the rate of disappearance of admixed nitrite $(0.01 M)$ when continuously perfused through soil (see Fig. 4). The retardation by glycine, alanine or sodium glutamate is not large and may perhaps be explained on the grounds that the amino-acids themselves give rise to sufficient nitrite, as an intermediate in their oxidation, to maintain the initial nitrite-level for some time. Cysteine produces a greater retardation, but dl-methionine again evinces a highly inhibitory effect on this aspect of

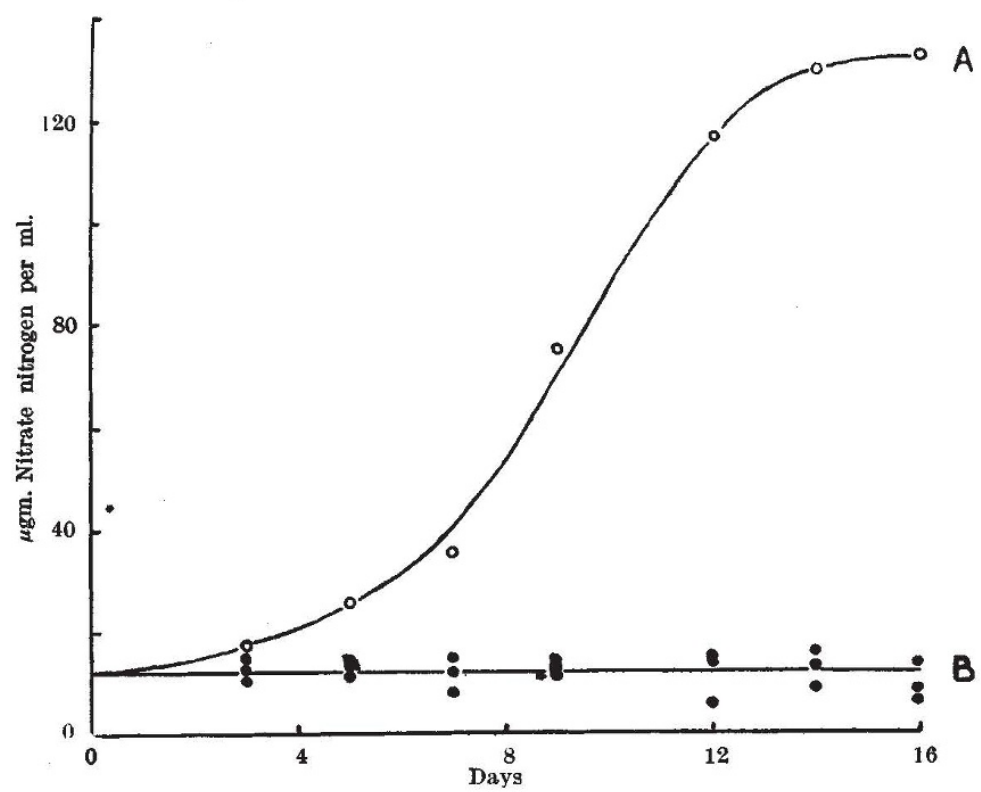

Fig. 3. Fffect of thiourea $(0.0003 M)$ on nitrate formation from $(0.01 M)$ ammonium chloride

$A$, Ammonium chlcride ; $B$, ammonium chloride and thiourea 
metabolism of nitrifying cells, are now known to be carcinogens. The mode of action of these substances in the body is quite unknown, but the question arises as to whether it is possible that they may be acting by affecting some phase of ammonia metabolism in animal tissue. This problem is now engaging our attention.

\section{Manometric Studies on Enriched Soils}

Soils that have been enriched or saturated with organisms attacking certain substrates may be conveniently investigated by the conventional Warburg manometric techniques. A fow typical results will be quoted although details of the technique will be given in full in later papers. It has been possible to show that ammonium salts, and nitrite, take up the expected quantities of oxygen for conversion to nitrate, using the appropriate washed enriched soils as the catalytic agents. The same technique allows the effects of poisons on the enzyme systems of enriched



Fig. 5. Effect of ethyl urethane on nitrate formation from ammonium chloride during $-\bullet-, 0.01 M$ ammonium chloride; $\triangle-\bigcirc-, 0.01 M$ ammonium chloride and $0.1 \%$ ethyl urethane soils to be explored quantitatively. The rate of oxygen uptake by an enriched soil in the presence of the substrate used for enriching the soil with the organisms which metabolize it is usually constant, and the effect of an inhibitor can be assessed with some accuracy. An example of the inhibitory effect of thiourea on the oxygen uptake of a soil enriched with nitrifying organisms in the presence of ammonium ions is shown in Fig. 6.

Table 4

Rates of extra oxygen uptake by a nitrite-enriched soil at $37^{\circ} \mathrm{C}$. in $\mathrm{c} \mathrm{mm}$. $/ \mathrm{hr}$.

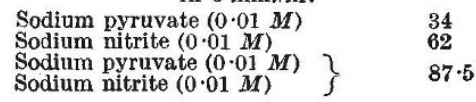

On the other hand, the presence of a number of organic molecules such as pyruvate does not influence



Fig. 4. Effects of amino-acids $(0.01 M)$ on nitrite utilization during soil perfusion

$0-0-$, Nitrite alone ; $x-\times-$, with alanine ; $\odot-\odot-$, with aspartate; $\square-\square-$, with glycine; $\Phi=\Phi-$, with

the rate of nitrite oxidation by the nitrifying organisms. The rates of extra oxygen are additive, or nearly so, on enriched soils, as shown by the results in Table 4.

These results prove that organic matter per se does not influence the metabolism of nitrite by the nitrifying organisms.

Manometric experiments have proved to be of great value not only in assessing the activities of enriched soils or in studying the effects of substrates or of poisons in soil processes, but also in investigating the nature of the catalytic systems or enzymes in the organisms that enrich the soil.

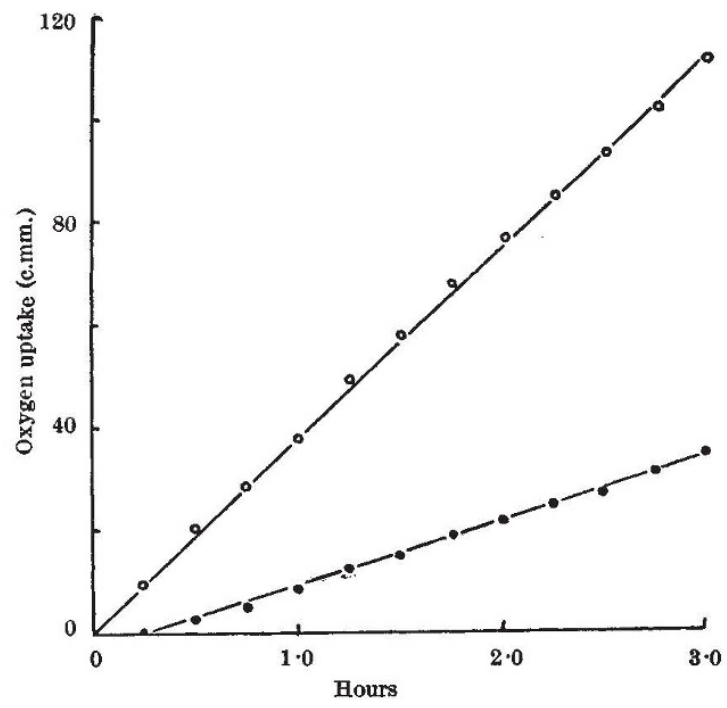

Fig. 6. Iffect of thiourea on the oxygen uptake of an enriched soil in the presence of ammonium chloride at $37^{\circ} \mathrm{C}$.

○ $-\mathrm{O},, 0.01 M$ ammonium chloride; -,$- 0.01 M$ 


\section{Metabolism of Pyruvic Oxime}

Pyruvic oxime, as shown by Lees and Quastel ${ }^{1}$, undergoes rapid nitrification in soil during continuous perfusion. It was thought by these authors that this molecule might be intermediate in the process of ammonia conversion into nitrate during soil nitrification: This, however, is not the case, since further studies-both perfusion and manometric-have shown :

(a) that ethyl urethane and methionine, which inhibit nitrification of ammonia in soil, have no inhibitory effects on the nitrification of pyruvic oxime; potassium chlorate also has no action.

(b) that soils enriched with ammonia- or nitriteoxidizing organisms cannot oxidize pyruvic oxime immediately though they oxidize ammonium ions or nitrite respectively.

(c) that soils enriched with organisms oxidizing pyruvic oxime by continuous perfusion with it cannot oxidize ammonium ions. Typical figures supporting these statements are given in Table 5.

\section{Table 5}

(A) Pyruvic oxime enriched sofl. Oxygen uptakes in $3 \mathrm{hr}$. in c.mm. $\begin{array}{lr}\text { Water at } 37^{\circ} \mathrm{C} . & 155 \\ \text { Pyruvic oxime }(0.01 \mathrm{M}) & 380 \\ \text { Ammonium chloride }\left(0^{\circ} \cdot 01 \mathrm{M}\right) & 155\end{array}$

(B) Perfusion of ammonium chloride enriched soil. Percentage (B) Perfusion of ammonium chloride enriched soil. Percentage
nitrogen appearing as nitrite in $24 \mathrm{hr}$. $0 \cdot 001 M$ potassium chlorate Ammonium chloride $(0.01 M)$ Pyruvic oxime $(0.01 \mathrm{M})$

31

(C) Perfusion of fresh soil. Percentage nitrogen appearing as nitrite in four days. $0.001 M$ potassium chlorate present in each. Methionine $(0.01 M)$
Methionine $(0.01 M)$ and
pyruvic oxime $(0.01 M)$
Pyruvic oxime $(0.01 M)$

These results point to the conclusion that soils contain organisms, presumably heterotrophic, that can bring about a speedy oxidation of pyruvic oxime to nitrite. Oxalacetic oxime will also undergo nitrification, but no other oxime yet studied has been found to have this property. Oximes of acetone, formaldehyde, acetoacetic ester and benzoin have been tested and found to be inert. Moreover, they do not inhibit the nitrification of pyruvic oxime. The only substances yet found to inhibit the nitrification of pyruvic oxime in soil are sodium azide and sodium cyanide, both vigorous respiratory poisons.

Work, in collaboration with Dr. J. W. Stevenson, of the Bacteriology Department, McGill University, is in progress and has now resulted in the isolation of the organisms responsible from the enriched soils.

Whether or not pyruvic oxime is an intermediate in nitrogen metabolism of soil bacteria is a matter for further investigation. It is clear, however, that the presence in soil of a group of organisms that can rapidly nitrify pyruvic oxime without the intervention of the autotroph Nitrosomonas points to the possibility that the process of nitrification in soil may not be wholly accomplished by the autotrophic organisms and that the intervention of heterotrophs bringing about a direct nitrification of organic nitrogen compounds may take place.

\footnotetext{
'Lees, H., and Quastel, J. H., Chem. and Indust., 26, 238 (1944); Biochem. J., 40, 803 (1946).

${ }^{2}$ Audus, L. J., Nature, 158, 419 (1946).

'Meyerhof, O., Pflüg. Arch. ges. Physiol., 164, 253 (1916); 165, 229 (1916); 166, 240 (1917).

4 Lees, H., and Quastel, J. H., Nature, 155, 276 (1945).
} INTERNATIONAL COUNCIL FOR THE EXPLORATION OF THE SEA

$\mathrm{O}^{\mathrm{N}}$ the invitation of the British Government, the International Council for the Exploration of the Sea (Conseil Permanent.International pour l'Exploration de la Merfarsinged to hold its thirty-seventh annual megting $\boldsymbol{A}$ Edinburgh during October 3-11. The ocgasipn was the more welcome since it was the first on which the Gpuncil had met in Scotland, while it is twenty year $\$$ ince it last met in Great Britain (Lqddon) in (Cotobbr 1929. Arrangements for the meeting were hade by the Scottish Home Department.

The Council met under the presidency of Dr. K. A. Andersson of Sweden, who was re-elected president for the year 1949-50. Government delegates and experts from Iceland, Norway, Sweden, Denmark, Finland, Holland, Belgium, France, Spain, Portugal, Eire and the United Kingdom were present, and were very glad to welcome observers from the United Nations Food and Agriculture Organisation, from the United States and from Australia, together with visitors from various marine laboratories. It was regretted that representetives from Poland were unable to be present. H.M.S. Cygnet and H.M.S. Welcome (Fishery Protection Flotilla) visited the port of Leith for this occasion, as well as research vessels from Sweden, Belgium, France, England and Scotland, all of which were on view during the meeting.

The members of the Council and visitors were welcomed by the Lord Provost of Edinburgh, Sir Andrew Murray, and the joint Parliamentary UnderSecretary of State for Scotland, Mr. J. J. Robertson, when the Council held its first meeting in the City Chambers on October 3. Reference was made at this meeting to the loss sustained by the Council in the death during 1949 of Prof. Martin Knudsen of Copenhagen. Subsequent meetings of the Council were held in the Department of Zoology on the invitation of the University of Edinburgh.

Special arrangements were made to precede the meetings of the Council by a conference of herring experts from the various interested countries. This was held in St. Andrew's House, Edinburgh, during September 29-October 1 and was followed by a special 'herring meeting' of the Council on October 4, when the chief item was an address by Prof. A. C. Hardy (Oxford), who reviewed the whole field of herring research and made stimulating proposals for its development.

During the conference of herring experts, the various countries reported on their work since the previous meeting held in Aberdeen in 1946, and great interest was shown in the preliminary recaptures which have been obtained by Sweden, Denmark and Scotland following new methods of herring tagging. Previous attempts to label herring with external tags have been unsuccessful, so that future recaptiures of such herring promise to provide greatly needed information about their migrations, growth, etc. A recommendation was passed that every effort should be made by all countries concerned with herring fisheries to undertake further tagging experiments, and in particular to compare the efficiency of the different types of tags in order to select those most likely to give a high percentage of recaptures.

Much interest was shown also in the preliminary results of applying the American and Canadian 